\title{
Hypermethylation-mediated reduction of WWOX expression in intraductal papillary mucinous neoplasms of the pancreas
}

\author{
S Nakayama ${ }^{1,2}$, S Semba*, , N Maeda', M Matsushita', Y Kuroda ${ }^{2}$ and H Yokozaki' \\ 'Division of Pathology, Department of Pathology, Kobe University Graduate School of Medicine, Kobe, Japan; '2Division of Gastroenterological Surgery, \\ Department of Surgery, Kobe University Graduate School of Medicine, Kobe, Japan
}

\begin{abstract}
We have previously shown that WW domain-containing oxidoreductase (WWOX) has tumour-suppressing effects and that its expression is frequently reduced in pancreatic carcinoma. In this study, we examined WWOX expression in intraductal papillary mucinous neoplasm of the pancreas (IPMN) to assess the function of WWOX in pancreatic duct tumourigenesis using immunohistochemistry and methylation-specific polymerase chain reaction analysis. Among 4I IPMNs including intraductal papillary mucinous adenomas (IPMAs) and intraductal papillary mucinous carcinomas (IPMCs), loss or reduced WWOX immunoreactivity was detected in $3(15 \%)$ of 20 IPMAs and 17 (81\%) of 21 IPMCs. In addition, hypermethylation of the WWOX regulatory site was detected in I (33\%) of 3 WWOX(-) IPMAs and 9 (53\%) of I 7 WWOX(-) IPMCs, suggesting that hypermethylation may possibly be important in the suppression of WWOX expression. Reduction of WWOX expression was significantly correlated with a higher Ki-67 labelling index but was not correlated with the ssDNA apoptotic body index. Interestingly, decreased WWOX expression was significantly correlated with loss of SMAD4 expression in these IPMNs. The results indicate that downregulation of WWOX expression by the WWOX regulatory region hypermethylation is critical for transformation of pancreatic duct.

British Journal of Cancer (2009) I 00, |438-|443. doi:I0.1038/sj.bjc.6604986 www.bjcancer.com
\end{abstract}

Published online 7 April 2009

(c) 2009 Cancer Research UK

Keywords: WW domain-containing oxidoreductase; SMAD4; intraductal papillary mucinous neoplasm of the pancreas; hypermethylation

Intraductal papillary mucinous neoplasm of the pancreas (IPMN) accounts for an estimated $1-3 \%$ of all pancreatic exocrine tumours and this pancreatic duct-derived neoplasm is characterised by abundant mucin production, dilated ducts and a more favourable prognosis than that in invasive ductal carcinoma of the pancreas (IDC; Japan Pancreas Society, 2003; Hruban et al, 2004). Histologically, intraductal components of IPMN are classified into adenoma (intraductal papillary mucinous adenoma, IPMA) and carcinoma in situ (intraductal papillary mucinous carcinoma, IPMC). Interestingly, some patients occasionally have IDC derived from IPMN, suggesting that IPMN corresponds to a precursor lesion, which may potentially progress to IDC (Yamao et al, 2000; Sohn et al, 2001). Genetic alterations in IPMN have been identified, including mutations in the K-RAS (Z'Graggen et al, 1997; Schönleben et al, 2007), SMAD4 (Hruban et al, 2004), TP53 (Sessa et al, 1994) and PIK3CA genes (Schönleben et al, 2006), and have been shown to activate the mitogen-activated protein kinase and phosphatidylinositol-3 kinase pathways (Sessa et al, 1994; Semba et al, 2003). However, much remains unknown about the molecular background of the development and progression of IPMN.

*Correspondence: Dr S Semba, Division of Pathology, Department of Pathology, Kobe University Graduate School of Medicine, 7-5-1 Kusunoki-cho, Chuo-ku, Kobe 650-0017, Japan;

E-mail: semba@med.kobe-u.ac.jp

Received 8 January 2009; revised 9 February 2009; accepted 19 February 2009; published online 7 April 2009
The WW domain-containing oxidoreductase (WWOX) gene is a tumour suppressor gene that spans a common chromosomal fragile site, FRA16D (16q23.3-24.1). Loss of heterozygosity (LOH) at the WWOX locus, hypermethylation of the WWOX regulatory site and resultant reduction of WWOX expression have been reported in various human malignancies (Paige et al, 2001; Driouch et al, 2002; Kuroki et al, 2002; Iliopoulos et al, 2005). Indeed, restoration of the WWOX gene suppresses cell proliferation and induces apoptosis in various human malignancies, including in cells derived from lung cancer (Fabbri et al, 2005), prostate cancer (Qin et al, 2006) and breast cancer (Aqeilan et al, 2007). Recent studies have shown that the WW1 domain of the WWOX protein has an essential function in its tumour suppressor function by regulating the subcellular localisation of p73 (Aqeilan et al, 2004a) and AP-2 $\gamma$ (Aqeilan et al, $2004 \mathrm{~b}$ ), both of which contain the proline-rich ligand 'PPXY' motif.

We previously showed that the WWOX gene promoter is frequently hypermethylated and WWOX expression frequently reduced in IDC cases (Kuroki et al, 2004; Nakayama et al, 2008). Much as in other human malignancies, restoration of the WWOX gene effectively suppressed the cell growth and induced caspasedependent apoptosis in pancreatic cancer-derived cells in conjunction with an increase in SMAD4 expression (Nakayama et al, 2008). In this study, we assessed WWOX expression in IPMN (IPMA and IPMC) to know whether suppression of WWOX expression is common event during tumourigenesis of these pancreatic duct lesions, IDC and IPMN. 


\section{MATERIALS AND METHODS}

\section{Tissue samples}

Formalin-fixed and paraffin-embedded specimens from 41 IPMNs (20 cases of IPMA and 21 cases of IPMC) surgically removed at Kobe University Hospital (Kobe, Japan) were used. Fifteen men and five women (average age, 71.4 \pm 7.4 years; age range, 54-82 years) had IPMAs, and eight men and thirteen women (average age, $66.6 \pm 8.9$ years; age range, $47-80$ years) had IPMCs. Informed consent was obtained from all patients and the study was approved by the Kobe University Institutional Review Board. Histological examination was performed according to the Classification of Pancreatic Carcinoma established by the Japan Pancreas Society (2003).

\section{Immunohistochemistry (IHC)}

A modified version of the immunoglobulin enzyme bridge technique with an LSAB kit (Dako, Glostrup, Denmark) was used. Deparaffinised and rehydrated sections were autoclaved to retrieve antigenicity. After blocking of endogenous peroxidase and non-specific reactions, the primary antibodies against WWOX (Imgenex, San Diego, CA, USA), SMAD4 (Cell Signaling, Beverly, MA, USA), Ki-67 (Dako) and ssDNA (Dako) were applied to sections, which were then incubated with biotinylated monkey anti-rabbit IgG. Streptavidin conjugated to horseradish peroxidase was used for the immersion in with 3,3-diaminobenzidine. Sections were counterstained with hematoxylin.

The degree of WWOX and SMAD4 expression was graded according to the number of stained cells and the staining intensity in individual cells: negative, almost no positive cells or $<50 \%$ of tumour cells showed weak immunoreactivity; positive, $>50 \%$ of tumour cells showed weak immunoreactivity or tumour cells showed intense immunoreactivity. The Ki-67 labelling index (LI) was determined by counting the positive cells in a total of 1000 tumour cells, whereas the ssDNA apoptotic body index (ssDNA ABI) was determined by counting the ssDNA-positive cells in 10 high-power fields. Detection of ssDNA-positive cells is useful for evaluation of apoptotic tumour cells, as is the terminal deoxynucleotidyl transferasemediated deoxyuridine triphosphate-biotin nick end-labelling method (Naruse et al, 1994; Kawarada et al, 1998; Watanabe et al, 1999).

\section{Statistical analysis}

We used the $\chi^{2}$-test and Mann-Whiney $U$-test to evaluate the relationship between WWOX immunoreactivity and the clinicopathological findings. $P$-values less than 0.05 were considered statistically significant.

\section{Cell culture and treatment}

Human pancreatic cancer cell line BxPC-3 was obtained from the American Type Culture Collection (Manassas, VA, USA). Cells were cultured in RPMI 1640 medium containing 10\% fetal bovine serum at $37^{\circ} \mathrm{C}$ in an atmosphere containing $5 \% \mathrm{CO}_{2}$. BxPC-3 cells were seeded in a $100 \mathrm{~mm}$ plate at a density of $1 \times 10^{6}$ cells. After $24 \mathrm{~h}$, cells were treated with DNA methyltransferase inhibitor 5-aza-2'-deoxycytidine (5-aza-dC; Sigma-Aldrich, St Louis, MO, USA) and histone deacetylase inhibitor trichostatin A (TSA; Sigma-Aldrich), either alone or in combination. The medium was changed every day for 5 days. For the treatment combining 5 -aza-dC and TSA, cells were cultured in the presence of 5-aza-dC $(0-5 \mu \mathrm{M})$ for 4 days and then treated with TSA $(1 \mu \mathrm{M})$ for another $24 \mathrm{~h}$.
Methylation-specific polymerase chain reaction (MSP) analysis

Genomic DNA was treated with sodium bisulphite (EpiTect Bisulfite kit; Qiagen, Hilden, Germany) and was analysed by MSP using primer sets located within the WWOX regulatory site (Iliopoulos et al, 2005) for MSP (methylated), 5'-GCGAGTGGATT CGGTAGCGGGCGA-3' and 5'-CCGTATCGTCCAACCCCGCGT-3'; and for MSP (unmethylated), 5'-GTGAGTGGATTTGGTAGTGG GTGA- $3^{\prime}$ and $5^{\prime}$-CCATATCATCCAACCCCACAT $-3^{\prime}$. The PCR amplification consisted of 35 cycles (denaturation at $94^{\circ} \mathrm{C}$ for $30 \mathrm{~s}$, annealing at $62^{\circ} \mathrm{C}$ for $30 \mathrm{~s}$ and extension at $72^{\circ} \mathrm{C}$ for $1 \mathrm{~min}$ ) and was followed by a final extension for $10 \mathrm{~min}$ at $72^{\circ} \mathrm{C}$. The PCR products were resolved by electrophoresis on a $2 \%$ agarose gel.

\section{Bisulphite genomic sequence analysis}

Bisulphite sequence analysis was performed to check the methylation status in BxPC-3 cells and IPMN cases. The extracted genomic DNAs were subjected to bisulphite modification and amplification of the $5^{\prime}$ region. The primers were designed from regions in which there are no CpG dinucleotides: 5'-TAAACTATACAAAATCCC AAAT- $3^{\prime}$ and $5^{\prime}$-GTTTTTGTAGGATTGGTTAGAA- $3^{\prime}$ (Iliopoulos et al, 2005). The PCR products were gel-purified using a QIAquick Gel Extraction kit (Qiagen) according to the manufacturer's instructions. Each amplified DNA sample was subcloned and applied to the ABI 310 DNA analyser using a BigDye Terminator kit (Applied Biosystems, Foster City, CA, USA).

\section{Western blotting}

Cells were lysed in a lysis buffer (50 mM Tris- $\mathrm{HCl}$ (pH 7.4), $125 \mathrm{~mm}$ $\mathrm{NaCl}, 0.1 \%$ Triton $\mathrm{X}$ and $5 \mathrm{~mm}$ ethylenediaminetetraacetic acid (EDTA)). Proteins $(20 \mu \mathrm{g})$ were separated by sodium dodecyl sulphate-polyacrylamide gel electrophoresis, electrotransferred onto an immunobilon-P membrane (Millipore, Billerica, MA, USA), and then immunoblotted with antibodies against WWOX and $\beta$-actin (Sigma-Aldrich). Horseradish-peroxidase-conjugated donkey anti-mouse IgG and sheep anti-rabbit IgG (GE Healthcare, Piscataway, NJ, USA) were used as secondary antibodies. Proteins were visualised using enhanced chemiluminescence.

\section{RESULTS}

\section{WWOX expression in IPMN and correlation with clinicopathological findings}

As a first step towards clarifying the function of WWOX in IPMN, we performed immunohistochemical analysis of WWOX expression in 41 IPMN cases. As in the adjacent normal pancreatic duct epithelium, abundant cytoplasmic WWOX expression was detected in IPMA, whereas WWOX expression was remarkably reduced in IPMC. Reduction or loss of WWOX expression was detected in 3 $(15 \%)$ of 20 IPMAs and $17(85 \%)$ of 21 IPMCs $(P<0.001$; Figure 1A).

Because the malignant potentials of these two subtypes of IPMN, IPMA and IPMC, are quite different, their associations with the clinicopathological findings were evaluated separately. The results are summarised in Table 1 . Negative immunoreactivity of WWOX was significantly correlated with greater dilation of the main duct $(P=0.006)$ in IPMAs and with older age $(P=0.022)$ in IPMCs. Restoration of the WWOX gene in pancreatic carcinoma PANC-1 (WWOX-negative) cells effectively suppressed cell growth and induced caspase-dependent apoptosis; we therefore estimated the possible relationship between low levels of WWOX expression and higher growth rate or infrequent incidence of apoptosis in IPMN. The Ki-67 LI was significantly higher in WWOX(-) IPMAs than WWOX $(+)$ IPMAs $(P<0.001)$, whereas no correlation was found 

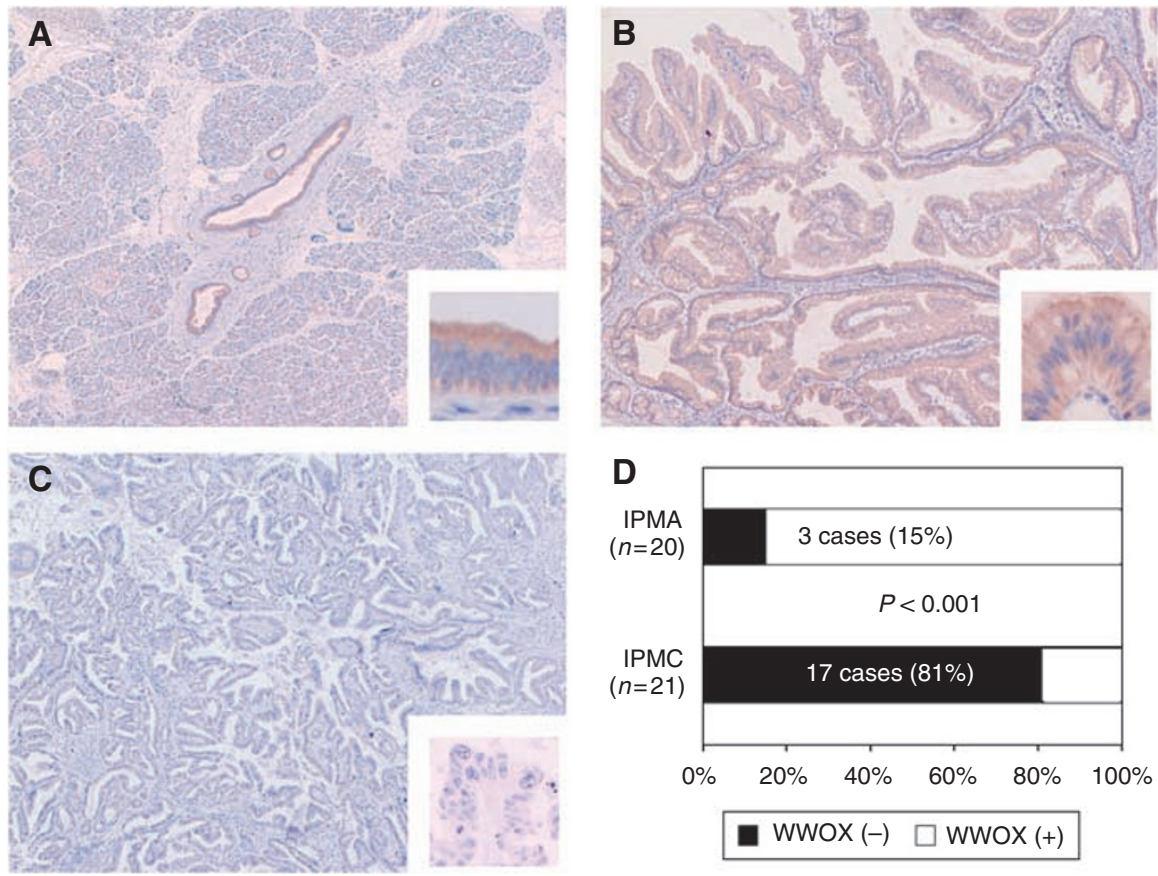

Figure I Immunohistochemistry (IHC) of WWOX expression. The degree of WWOX expression was graded according to the number of stained cells and the staining intensity in individual cells: negative, almost no positive cells or $<50 \%$ of tumour cells showed weak immunoreactivity; positive, $>50 \%$ of tumour cells showed weak immunoreactivity or tumour cells showed intense immunoreactivity. (A) Normal pancreatic ducts (original magnification $\times$ I00). (B) Intraductal papillary mucinous adenoma (IPMA, original magnification $\times 100$ ). (C) Intraductal papillary mucinous carcinoma (IPMC, original magnification $\times$ 100). Each specimen with high magnification $(\times 400)$ is also shown in insets. (D) Frequency of reduced or loss of WWOX expression in IPMA and IPMC

Table I Correlation of WWOX expression with clinicopathological findings in IPMA

\begin{tabular}{|c|c|c|c|}
\hline IPMA & $\begin{array}{c}\text { WwoX(-) } \\
(n=3)\end{array}$ & $\begin{array}{c}\text { Wwox(+) } \\
(n=17)\end{array}$ & $P$-value ${ }^{a}$ \\
\hline \multicolumn{4}{|l|}{ Age (years) } \\
\hline Average & $71.0 \pm 2.6$ & $69.9 \pm 7.9$ & 0.816 \\
\hline \multicolumn{4}{|l|}{ Gender } \\
\hline Male & $2 \%$ & $13 \%$ & 0.860 \\
\hline Female & $1 \%$ & $4 \%$ & \\
\hline \multicolumn{4}{|c|}{ Tumour size (mm) } \\
\hline Average & $20.7 \pm 12.5$ & $41.0 \pm 20.7$ & 0.121 \\
\hline \multicolumn{4}{|c|}{ Main duct (mm) } \\
\hline Average & $12.3 \pm 3.1$ & $5.6 \pm 3.4$ & 0.006 \\
\hline \multicolumn{4}{|l|}{ Location } \\
\hline Head & $3 \%$ & $12 \%$ & 0.399 \\
\hline Body/Tail & $0 \%$ & $5 \%$ & \\
\hline \multicolumn{4}{|l|}{ Tumour type } \\
\hline Main duct & $2 \%$ & $6 \%$ & 0.344 \\
\hline Branch & $1 \%$ & $11 \%$ & \\
\hline $\mathrm{Ki}-67 \mathrm{LI}^{\mathrm{b}}$ & $22.3 \pm 6.5$ & $5.1 \pm 5.1$ & $<0.001$ \\
\hline ssDNA ABI ${ }^{b}$ & $1.7 \pm 0.8$ & $1.4 \pm 0.9$ & 0.624 \\
\hline
\end{tabular}

IPMA = intraductal papillary mucinous adenoma; Ki-67 LI=Ki-67 labelling index; ssDNA ABI = ssDNA apoptotic body index. ${ }^{a} P$-value less than 0.05 was considered to be statistically significant. ${ }^{b} \mathrm{Ki}-67 \mathrm{LI}$ was determined by counting the positive cells in 1000 tumour cells, whereas the ssDNA ABI was determined by counting the ssDNApositive cells in 10 high-power fields. between the Ki-67 LI and WWOX expression status in IPMCs $(P=0.109)$. No difference was found in the ssDNA ABI of these IPMNs between the presence and absence of WWOX expression.

\section{Hypermethylation of the WWOX regulatory site in IPMN}

In pancreatic carcinoma cells and IDC tissue samples, a close correlation has been documented between hypermethylation of the WWOX regulatory region and low WWOX expression levels rather than LOH at the WWOX locus (Nakayama et al, 2008). In BxPC-3 (low WWOX expression) cells, frequent hypermethylation at the $W W O X$ regulatory sites was detected by bisulphite sequencing (Figure 2A). Representative results of cytosine-uracil (C-U) transition of the WWOX regulatory site are shown in Figure $2 \mathrm{~B}$. We confirmed that treatment with the demethylating agent 5 -aza-dC led to the restoration of WWOX expression at the protein level (Figure 2C). We then designed an MSP primer set within the WWOX regulatory region and investigated the incidence of hypermethylation-mediated suppression of WWOX expression in IPMN. Among 20 IPMNs with low WWOX expression, hypermethylation of the WWOX regulatory site was detected in $1(33 \%)$ of 3 WWOX(-) IPMAs and 9 of 17 (53\%) of WWOX(-) IPMCs (Figures 2D and E; Table 2).

\section{Association of SMAD4 expression with the WWOX status in IPMN}

Because we have previously shown that increased SMAD4 expression at the protein level can be induced by the transfection of WWOX-expressing vector into pancreatic cancer-derived PANC-1 cells (Nakayama et al, 2008), we also examined the SMAD4 expression in these IPMN cases (Figure 3A). In total, 13 


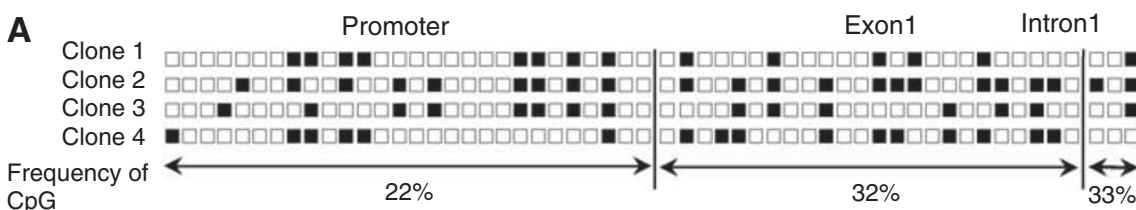
methylation

B

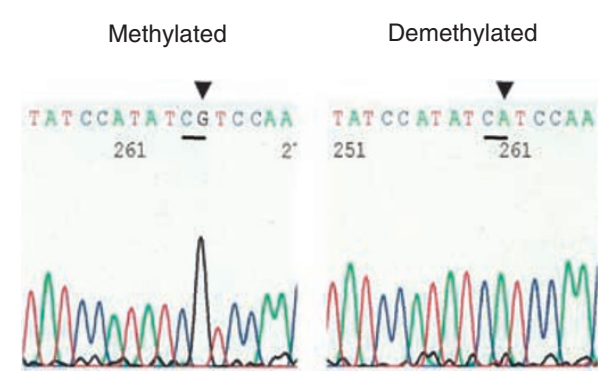

D

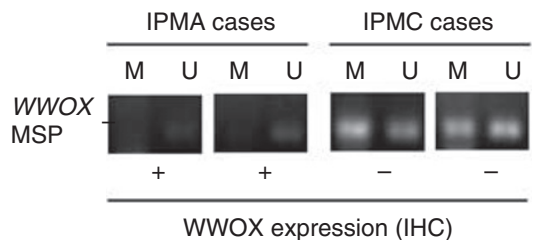

c

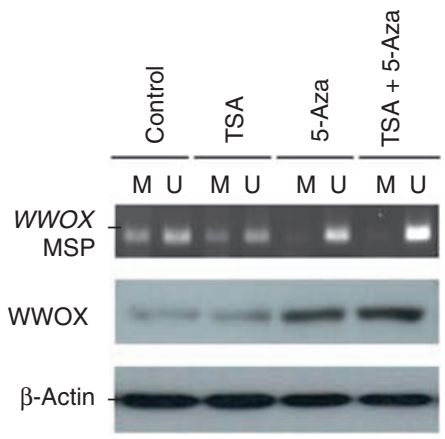

E

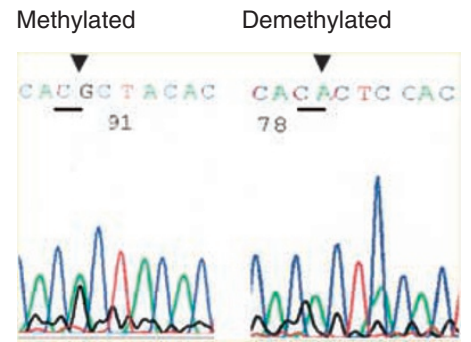

Figure 2 Hypermethylation-mediated downregulation of WWOX expression in intraductal papillary mucinous neoplasm of the pancreas (IPMN). (A) Results of bisulphite genomic sequence analysis at the WWOX regulatory site, including the promoter region, exon I and intron I. Filled boxes indicate methylation; open boxes indicate absence of methylation. (B) Representative results of bisulphite genomic sequence analysis of BxPC-3 cells. Arrowheads indicate the CpG island that demonstrated cytosine-uracil transition. (C) The methylation status of the WWOX regulatory CpG site determined by the methylation-specific PCR (MSP) analysis. BxPC-3 cells were treated with trichostatin A (TSA), 5-aza-2'-deoxycytidine (5-aza-dC) and a combination of the two drugs. Restored WWOX expression was confirmed by western blot analysis. $\beta$-Actin was used as a loading control. (D) Representative results of MSP analysis. The status of WWOX expression detected by IHC was also exhibited. (E) Representative results of bisulphite genomic sequence analysis of IPMA and IPMC. Arrowheads indicate the CpG island that demonstrated cytosine-uracil transition. M, methylated; $U$, unmethylated.

(32\%) of 41 IPMNs demonstrated loss of SMAD4 expression. Interestingly, loss of SMAD4 expression was detected only in 1 $(5 \%)$ of 21 WWOX( + ) IPMNs, whereas $12(60 \%)$ of 20 WWOX(-) IPMNs showed loss of SMAD4 expression $(P<0.001$; Figure $3 \mathrm{~B})$.

\section{DISCUSSION}

Intraductal papillary mucinous neoplasm of the pancreas is one of the unusual neoplasms derived from pancreatic duct epithelia and demonstrates both unusually favourable biological behaviour and a broad spectrum of cytoarchitectural atypia. In this study, we found frequent reduction of WWOX expression in IPMC, which was almost equivalent to the frequency of WWOX reduction in IDC (Nakayama et al, 2008). In turn, WWOX expression was relatively retained in most IPMAs, suggesting that reduced WWOX expression does not contribute to development of IPMA. In our previous study, we also reported that the expression of WWOX in pancreatic intraepithelial neoplasias (PanINs) tended to be suppressed in accord with the PanIN grade, which is determined by the morphological and cytogenetic cellular atypia (Nakayama et al, 2008). As in the case of other oncogenes (K-RAS) and tumour suppressor genes ( $p 16, p 53$ and SMAD4), downmodulation of WWOX expression may be important during multi-step pancreatic duct carcinogenesis, particularly at the late stage (Hahn et al, 1996; Hruban et al, 2000).

Carcinoma cell lines and primary tumours exhibit hemizygous or homozygous deletion with end points within fragile regions of the human genome, particularly within the most active common fragile site, FRA3B, encompassed by the FHIT gene (Iliopoulos et al, 2006). Similarly, for the FHIT gene and the other fragile siterelated genes, deletion at the WWOX (FRA16D) locus and resultant loss of WWOX expression have been shown to promote cell transformation and immortalisation in various human malignancies (Paige et al, 2001; Driouch et al, 2002; Kuroki et al, 2002); however, the incidence of $\mathrm{LOH}$ was infrequent in pancreatic carcinoma (Kuroki et al, 2004; Nakayama et al, 2008) and we could not detect $\mathrm{LOH}$ in this series of IPMNs (data not shown). Indeed, Fukushige et al (1998) did not detect aberrant copy numbers of DNA sequences on the WWOX locus (16q23.3-24.1) in pancreatic adenocarcinomas by the comparative genomic hybridisation method. Taken together, these results indicated that hypermethylation at the $W W O X$ regulatory site, but not $\mathrm{LOH}$, is a critical for the suppression of WWOX transcripts during pancreatic duct carcinogenesis. Recently, Irizarry et al (2009) reported that most methylation alterations in colon cancer occur not in promoters, and also not in $\mathrm{CpG}$ islands, but in sequences up to $2 \mathrm{~kb}$ distant called 'CpG island shore', using comprehensive high-throughput 
Table 2 Correlation of WWOX expression with clinicopathological findings in IPMC

\begin{tabular}{|c|c|c|c|}
\hline IPMC & $\begin{array}{c}\text { WWOX(-) } \\
(n=17)\end{array}$ & $\begin{array}{c}\text { WWOX(+) } \\
(n=4)\end{array}$ & $P$-value ${ }^{a}$ \\
\hline \multicolumn{4}{|l|}{ Age (years) } \\
\hline Average & $68.7 \pm 7.6$ & $57.8 \pm 9.1$ & 0.022 \\
\hline \multicolumn{4}{|l|}{ Gender } \\
\hline Male & $7 \%$ & $1 \%$ & 0.502 \\
\hline Female & $10 \%$ & $3 \%$ & \\
\hline \multicolumn{4}{|c|}{ Tumour size (mm) } \\
\hline Average & $61.9 \pm 32.9$ & $50.0 \pm 24.5$ & 0.507 \\
\hline \multicolumn{4}{|c|}{ Main duct (mm) } \\
\hline Average & $9.5 \pm 3.8$ & $5.8 \pm 1.7$ & 0.071 \\
\hline \multicolumn{4}{|l|}{ Location } \\
\hline Head & $12 \%$ & $3 \%$ & 0.684 \\
\hline Body/Tail & $5 \%$ & $1 \%$ & \\
\hline \multicolumn{4}{|l|}{ Tumour type } \\
\hline Main duct & $14 \%$ & $3 \%$ & 0.852 \\
\hline Branch & $3 \%$ & $1 \%$ & \\
\hline $\mathrm{Ki}-67 \mathrm{LI}^{\mathrm{b}}$ & $27.6 \pm 10.8$ & $14.4 \pm 3.3$ & 0.109 \\
\hline ssDNA ABI & $1.5 \pm 1.2$ & $1.2 \pm 0.4$ & 0.767 \\
\hline
\end{tabular}

IPMC = intraductal papillary mucinous carcinoma; $\mathrm{Ki}-67 \mathrm{LI}=\mathrm{Ki}-67$ labelling index ssDNA ABI $=$ ssDNA apoptotic body index. ${ }^{a} P$-value less than 0.05 was considered to be statistically significant. ${ }^{b} \mathrm{Ki}-67 \mathrm{LI}$ was determined by counting the positive cells in 1000 tumour cells, whereas the ssDNA ABI was determined by counting the ssDNApositive cells in 10 high-power fields.

array-based relative methylation analysis. In the future, we would like to identify such a tissue-specific conserved region for WWOX expression to explain frequent reduction of WWOX expression in the development of IPMC from IPMA.

Loss of WWOX expression was significantly correlated with Ki-67 LI but not with ssDNA ABI. Also, we noted that reduction of WWOX expression was associated with the status of SMAD4 expression. The SMAD4 gene (also referred as DPC4, for deleted in pancreatic carcinoma locus 4) shares characteristics with typical tumour suppressor genes, including involvement in the transforming growth factor- $\beta$ signalling (Hahn et al, 1996). About half of pancreatic carcinomas contain either homozygous deletions of the SMAD4 locus or inactivating mutations in one allele associated with $\mathrm{LOH}$, and a resultant loss of SMAD4 expression in pancreatic carcinoma has been documented (Hahn et al, 1996; Wilentz et al, 2000). Takahashi et al (2004) investigated the SMAD4 status in the intraductal carcinoma component of IDC and found that $20-59 \%$ of carcinomas in situ expressed SMAD4, which corresponds to our data obtained in this study. The molecular mechanism underlying the simultaneous negative regulation of WWOX and SMAD4 levels is still unknown; according to our previous results, however, restoration of WWOX expression increased SMAD4 expression at the protein level, but not at the mRNA level, suggesting the WWOX-mediated post-transcriptional regulation of SMAD4 levels (Nakayama et al, 2008). SMAD4 can be proteasomally degraded after polyubiquitination by SMURF1 and SMURF2 E3 ligase complexes, which possess the WW domain (Morèn et al, 2003, 2005). Hence, we estimate that SMURFs and WWOX may competitively bind to the SMAD4-binding protein SMAD2 and SMAD7, both of which contain the PPXY motif, consequently leading inhibition of SMURF-related SMAD4 degradation. However, further investigation will be necessary to elucidate the mechanism by which SMAD4 levels can be increased by WWOX in
A
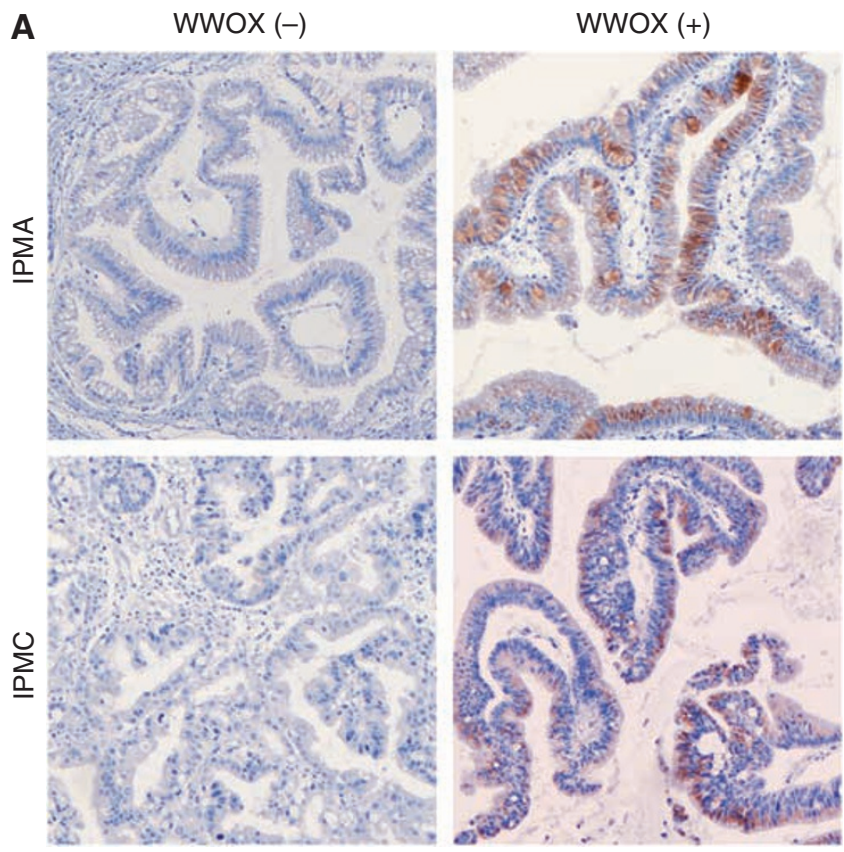

B

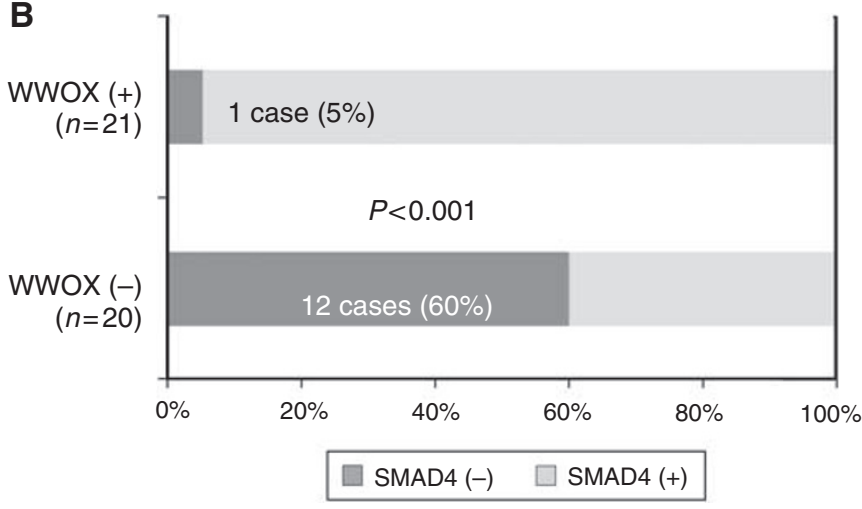

Figure 3 Reduced SMAD4 expression is associated with the WWOX status in IPMN. The degree of SMAD4 expression was graded according to the number of stained cells and the staining intensity in individual cells: negative, almost no positive cells or $<50 \%$ of tumour cells showed weak immunoreactivity; positive, $>50 \%$ of tumour cells showed weak immunoreactivity or tumour cells showed intense immunoreactivity. (A) Representative $\mathrm{IHC}$ results of SMAD4 expression in WWOX $(+)$ and WWOX $(-)$ IPMNs (original magnification $\times 100)$. (B) Frequency of reduced or loss of SMAD4 expression in WWOX $(+)$ and WWOX $(-)$ IPMNs.

IPMN. We assume that downregulation of WWOX is one of the critical events during the progression and development of IPMN, particularly at the late step of malignant transformation of pancreatic duct lesions, in addition to loss of SMAD4 expression.

\section{ACKNOWLEDGEMENTS}

This study was supported by grant-in-aid for Cancer Research from the Ministry of Health, Labor and Welfare of Japan (14-7 and 20-12) and grant-in-aid for Scientific Research (C-19590347) from the Japan Society for Promotion of Science. 


\section{REFERENCES}

Aqeilan RI, Palamarchuk A, Weigel RJ, Herrero JJ, Pekarsky Y, Croce CM (2004b) Physical and functional interactions between the Wwox tumor suppressor protein and the AP- $2 \gamma$ transcription factor. Cancer Res 64: $8256-8261$

Aqeilan RI, Pekarsky Y, Herrero JJ, Palamarchuk A, Letofsky J, Druck T, Trapasso F, Han SY, Melino G, Huebner K, Croce CM (2004a) Functional association between Wwox tumor suppressor protein and p73, a p53 homolog. Proc Natl Acad Sci USA 101: 401-406

Aqeilan RI, Trapasso F, Hussain S, Costinean S, Marshall D, Pekarsky Y, Hagan JP, Zanesi N, Kaou M, Stein GS, Lian JB, Croce CM (2007) Targeted deletion of Wwox reveals a tumor suppressor function. Proc Natl Acad Sci USA 104: 3949-3954

Driouch K, Prydz H, Monese R, Johansen H, Lidereau R, Frengen E (2002) Alternative transcripts of the candidate tumor suppressor gene, WWOX, are expressed at high levels in human breast tumors. Oncogene 21: $1832-1840$

Fabbri M, Iliopoulos D, Trapasso F, Aqeilan RI, Cimmino A, Zanesi N, Yendamuri S, Han SY, Amadori D, Huebner K, Croce CM (2005) WWOX gene restoration prevents lung cancer growth in vitro and in vivo. Proc Natl Acad Sci USA 102: 15611 - 15616

Fukushige S, Furukawa T, Satoh K, Sunamura M, Kobari M, Koizumi M, Horii A (1998) Loss of chromosome $18 \mathrm{q}$ is an early event in pancreatic duct tumorigenesis. Cancer Res 58: $4222-4226$

Hahn SA, Schutte M, Hoque AT, Moskaluk CA, da Costa LT, Rozenblum E, Weinstein CL, Fischer A, Yeo CJ, Hruban RH, Kern SE (1996) DPC4, a candidate tumor suppressor gene at human chromosome 18q21.1. Science 271: $350-353$

Hruban RH, Goggins M, Parsons J, Kern SE (2000) Progression model for pancreatic cancer. Clin Cancer Res 6: 2969-2972

Hruban RH, Takaori K, Klimstra DS, Adsay NV, Albores-Saavedra J, Biankin AV, Biankin SA, Compton C, Fukushima N, Furukawa T, Goggins M, Kato Y, Klöppel G, Longnecker DS, Lüttges J, Maitra A, Offerhaus GJ, Shimizu M, Yonezawa S (2004) An illustrated consensus on the classification of pancreatic intraepithelial neoplasia and intraductal papillary mucinous neoplasms. Am J Surg Pathol 28: $977-987$

Iliopoulos D, Guler G, Han SY, Druck T, Ottey M, McCorkell KA, Huebner K (2006) Roles of FHIT and WWOX fragile genes in cancer. Cancer Lett 232: $27-36$

Iliopoulos D, Guler G, Han SY, Johnston D, Druck T, McCorkell KA, Palazzo J, McCue PA, Baffa R, Huebner K (2005) Fragile genes as biomarkers: epigenetic control of WWOX and FHIT in lung, breast and bladder cancer. Oncogene 24: 1625-1633

Irizarry RA, Ladd-Acosta C, Wen B, Wu Z, Montano C, Onyango P, Cui H, Gabo K, Rongione M, Webster M, Ji H, Potash JB, Sabunciyan S, Feinberg AP (2009) The human colon cancer methylome shows similar hypo- and hypermethylation at conserved tissue-specific $\mathrm{CpG}$ island shores. Nat Genet 41: $178-186$

Japan Pancreas Society (2003) Classification of Pancreatic Carcinoma. 2nd edn, Kanehara: Tokyo

Kawarada Y, Miura N, Sugiyama T (1998) Antibody against single-stranded DNA useful for detecting apoptotic cells recognizes hexadeoxynucleotides with various base sequences. J Biochem 123: $492-498$

Kuroki T, Trapasso F, Shiraishi T, Alder H, Mimori K, Mori M, Croce CM (2002) Genetic alterations of the tumor suppressor gene WWOX in esophageal squamous cell carcinoma. Cancer Res 62: 2258-2260

Kuroki T, Yendamuri S, Trapasso F, Matsuyama A, Aqeilan RI, Alder H, Rattan S, Cesari R, Nolli ML, Williams NN, Mori M, Kanematsu T, Croce CM (2004) The tumor suppressor gene WWOX at FRA16D is involved in pancreatic carcinogenesis. Clin Cancer Res 10: 2459-2465
Morèn A, Hellman U, Inada Y, Imamura T, Heldin CH, Moustakas A (2003) Differential ubiquitination defines the functional status of the tumor suppressor Smad4. J Biol Chem 278: $33571-33582$

Morèn A, Imamura T, Miyazono K, Heldin CH, Moustakas A (2005) Degradation of the tumor suppressor Smad4 by WW and HECT domain ubiquitin ligases. J Biol Chem 280: 22115-22123

Nakayama S, Semba S, Maeda N, Aqeilan RI, Huebner K, Yokozaki H (2008) Role of the WWOX gene, encompassing fragile region FRA16D, in suppression of pancreatic carcinoma cells. Cancer Sci 99: 1370-1376

Paige AJ, Taylor C, Taylor C, Hillier SG, Farrington S, Scott D, Porteous DJ, Smyth JF, Gabra H, Watson JE (2001) WWOX: a candidate tumor suppressor gene involved in multiple tumor types. Proc Natl Acad Sci USA 98: $11417-11422$

Qin HR, Iliopoulos D, Semba S, Fabbri M, Druck T, Volinia S, Croce CM, Morrison CD, Klein RD, Huebner K (2006) A role for the WWOX gene in prostate cancer. Cancer Res 66: 6477-6481

Schönleben F, Qiu W, Bruckman KC, Ciau NT, Li X, Lauerman MH, Frucht H, Chabot JA, Allendorf JD, Remotti HE, Su GH (2007) BRAF and KRAS gene mutations in intraductal papillary mucinous neoplasia/carcinoma (IPMN/IPMC) of the pancreas. Cancer Lett 249: 242-248

Schönleben F, Qiu W, Ciau NT, Ho DJ, Li X, Allendorf JD, Remotti HE, Su GH (2006) PI3CA mutations in intraductal papillary mucinous neoplasm/ carcinoma of the pancreas. Clin Cancer Res 12: 3851-3855

Semba S, Moriya T, Kimura W, Yamakawa M (2003) Phosphorylated Akt/ PKB controls cell growth and apoptosis in intraductal papillarymucinous tumor and invasive ductal adenocarcinoma of the pancreas. Pancreas 26: $250-257$

Sessa F, Solcia E, Capella C, Bonato M, Scarpa A, Zamboni G, Pellegata NS, Ranzani GN, Rickaert F, Klöppel G (1994) Intraductal papillarymucinous tumours represent a distinct group of pancreatic neoplasms: an investigation of tumour cell differentiation and K-ras, p53 and c-erbB2 abnormalities in 26 patients. Virchows Arch 425: 357-367

Sohn TA, Yeo CJ, Cameron JL, Iacobuzio-Donahue CA, Hruban RH, Lillemoe KD (2001) Intraductal papillary mucinous neoplasms of the pancreas: an increasingly recognized clinicopathologic entity. Ann Surg 234: $313-321$

Takahashi H, Oda T, Hasebe T, Aoyagi Y, Kinoshita T, Konishi M, Nakagohri T, Inoue K, Takahashi S, Kawahira H, Monden M, Ochiai A (2004) Biologically different subgroups of invasive ductal carcinoma of the pancreas: Dpc4 status according to the ratio of intraductal carcinoma components. Clin Cancer Res 10: $3772-3779$

Watanabe I, Toyoda M, Okuda J, Tenjo T, Tanaka K, Yamamoto T, Kawasaki H, Sugiyama T, Kawarada Y, Tanigawa N (1999) Detection of apoptotic cells in human colorectal cancer by two different in situ methods: antibody against single-stranded DNA and terminal deoxynucleotidyl transferase-mediated dUTP-biotin nick end-labeling (TUNEL) methods. Jpn J Cancer Res 90: 188-193

Wilentz RE, Su GH, Dai JL, Sparks AB, Argani P, Sohn TA, Yeo CJ, Kern S (2000) Immunohistochemical labeling for dpc4 mirrors genetic status in pancreatic adenocarcinomas: a new marker of DPC4 inactivation. Am J Pathol 156: $37-43$

Yamao K, Ohashi K, Nakamura T, Suzuki T, Shimizu Y, Nakamura Y, Horibe Y, Yanagisawa A, Nakao A, Nimuara Y, Naito Y, Hayakawa T (2000) The prognosis of intraductal papillary mucinous tumors of the pancreas. Hepatogastroenterology 47: 1129-1134

Z'graggen K, Rivera JA, Compton CC, Pins M, Werner J, Fernandez-del Castillo C, Rattner DW, Lewandrowski KB, Rustgi AK, Warshaw AL (1997) Prevalence of activating K-ras mutations in the evolutionary stages of neoplasia in intraductal papillary mucinous tumors of the pancreas. Ann Surg 226: $491-498$ 